\title{
How Philosophical is Informal Logic?
}

\section{JoHn Woops The University of Lethbridge}

\begin{abstract}
Consider the proposition, "Informal logic is a subdiscipline of philosophy". The best chance of showing this to be true is showing that informal logic is part of logic, which in turn is a part of philosophy. Part 1 is given over to the task of sorting out these connections. If successful, informal logic can indeed be seen as part of philosophy; but there is no question of an exclusive relationship. Part 2 is a critical appraisal of the suggestion that informal logic is applied epistemology. Part 3 examines the claim that informal logic has failed to penetrate into mainstream philosophy, and suggestions for amelioration are considered.
\end{abstract}

Résumé: Examinons la proposition, «La logique non formelle est une sous-discipline de la philosophier. La meilleure façon d'augmenter nos chances de montrer qu'elle est vraie est d'établir que la logique non formelle fait partie de la logique, qui en son tour fait partie de la philosophie. Cet article se divise en trois parties. Premièrement, on clarifie ces rapports. Si on réussit, la logique non formelle peut en effet faire partie de la philosophie, mais il n'est pas question d'un rapport exclusif. Deuxièmement, on évalue la suggestion que la logique non formelle est l'épistémologie appliquée. Troisièmement, on examine l'énoncé que la logique non formelle n'a pas réussi à se faire accepter par la philosophie traditionnelle, et des suggestions pour améliorer la situation.

Keywords: informal logic, logic argument, argumentation, logical form, formal logic, formal description, idealization, models, epistemology, philosophy, proper basicality, justification, relevance, acceptability, sufficiency.

I have a great deal of sympathy with the intentions of those philosophers who speak of "informal logic", but I don't think that any clarity is gained by using the term "logic" for what they are doing. [Hintikka (1985)]

\section{Logic}

\subsection{Logic as a Service Discipline}

Although logic has its own parochial objectives, it has always had additional ends in view. Aristotle wanted his logic for its rôle in a wholly general theory of argument. The theory of syllogisms was to serve as the logical core of the larger 
theory; but there was never any prospect of an identity between them. The father of logic wanted among other things, a theory of refutation, a theory that would discipline the distinction between good refutations and good-looking refutations or, as Aristotle himself put it, between genuine and sophistical refutations. There is no such account to be found in the theory of syllogisms as such. The theory of refutation stands apart from the syllogistic; but does so in a systematic way. It is a nonconservative extension of the logic of syllogisms.

Frege is the independent co-founder of modern logic, which would be an indispensable component in the reduction of arithmetic. Frege's motivation was entirely epistemological. He wanted to establish that, pace Kant, arithmetic was not a synthetic discipline. This would be done by showing that number theory reduces without relevant loss to the union of set theory and a second order functional calculus, both of which Frege took to be analytic. "Logicism" is the name of Frege's epistemological thesis, and not (I say in passing) what Johnson and Blair take it to be, viz., "the view that logical form (à la Russell) holds the key to understanding the structure of all arguments ..." (102), ${ }^{2}$

The arithmetic of Frege's interest was being revolutionized by Cantor and others. It was a theory that recognized actual but additively incompleteable infinities; arithmetic had gone transfinite. This encumbered the reduction process with two rather interesting challenges, one ontological and the other semantic. Ontologically it was necessary to have convincing examples of transfinite objects. Semantically it was necessary to show how discrete and exhaustive reference could be achieved within actually infinite domains. The first requirement was met by set theory, the second by the theory of quantification.

It is said that Aristotle is the originator of formal logic, and thus the progenitor of a tradition of which Frege was heir. This is a mistake. There are no formal languages in Aristotle's logic, and no express manipulation of what later would be called logical forms. If indeed Aristotle is the father of formal deductive logic, it cannot be true as Johnson and Blair claim that logical form is its "chief analytical tool." $(94)$ Nor is Aristotle's logic a theory of validity. Validity is presupposed in the syllogistic but it isn't analyzed; it is a theoretical primitive. ${ }^{3}$ Aristotle saw syllogisms as restrictions of valid arguments, and he saw such arguments in turn as decontextualized propositional abstractions from real-life interpersonal argumentative exchanges. ${ }^{4}$ Syllogisms are valid arguments which satisfy further conditions. These conditions conspire to make of the syllogistic the first stab ever at an intuitionistic, nonmonotonic, relevant and hyperconsistent logic; but that is another story. ${ }^{5}$ So here, too, I demur from Johnson and Blair. If Aristotle is the father of formal deductive logic, it cannot be true to say that validity is its "main evaluational function"(94). I must also part company with Hitchcock who holds that what "is new [about present-day informal logic] is the central focus on argumentation in natural language, as an interpersonal, social, purposive practice" (130). True, yes. New, no. 
Aristotle invented logic and pledged it to service in the general theory of argument, that is, of real-life argument, of argument on the hoof. ${ }^{6}$ There is nothing in Frege that answers to this interest. Frege was engineering a bold and ultimately unsustainable move in mathematical epistemics. Even Aristotle's syllogisms were constructions of natural language, but Frege distrusted natural languages to the point of obsessiveness. His first great accomplishment as a logician was his Begriffsschrift, an artificial language. In this Frege was at one with the other independent co-founder of modern logic. Peirce insisted that there could be no such thing as a logic of natural languages. He was equally set against practical logic. The two rejections are connected. Logic was starting to be understoodwith a hefty boost from Boole $\mathrm{e}^{7}$-as a theory which distributed its target properties by recursion over syntactic structures. The intended distribution procedures could not be made to work smoothly, or even at all, for the objects of ordinary grammar. It was necessary to have syntactic structures of appropriate sharpness and simplicity. To this end, the language of logic would now be in Weinstein's apt phrase a "stylized language". This precludes practical logic or, as Peirce would say, a logic of "vital affairs". Vital affairs can only be transacted in natural languagesthe languages of the trading floor, of love, of making war and biscuits. Vital affairs exceed the reach of logic properly understood.

Frege's Begriffsschrift shunned the standard structures of the grammar of natural languages. Broadly speaking the Begriffsschrift eschewed constructions which lend a language its intensional character. It was also a language purged of vagueness. To achieve this, the logical syntax of the Begriffsschrift would be an uninterpreted language save for the logical particles. Some logicians speak of such languages as formal languages. What is intended is not so much their artificiality as the devices employed to extensionalize and precisify, since in their natural state languages are neither extensional nor precise.

Other uses of "formal" are also common among logicians. In the 1967 Postscript to "On Formally Undecidable Propositions", Gödel cites with approval the work of Turing, and defines a formal system to be "any mechanical procedure for producing formulas". ${ }^{8}$ In this use, formal logic serves the still further ends of recursion theory, a response to the celebrated Entscheidungsproblem, and a precursor of computer science, i.e., the theory of algorithms. ${ }^{9}$ By the midpoint of the $20^{\text {th }}$ century the new formal logic - mathematical logic - had ramified into the four princely domains of proof theory, model theory, set theory and recursion theory.

It is easy to see that Aristotle, Frege and Turing were pursuing entirely different ends. This is frequently not understood by writers of our logic textbooks and by many of those who teach from them. There is an altogether entrenched disposition to tell students that logic is the theory of argument and/or of deductive reasoning (which is partly true of Aristotle and not true at all of Frege and Turing), and then to give as this logic a version of Frege's logic or (worse) of Turing's. 
And so we have it: In classrooms the world over Aristotle's targets were being chased down with Frege's ordnance or (worse) with Turing's. Small wonder that in the early 1970's students started voicing their skepticism about the prospects of modern symbolic logic producing anything like a theory of argument, still less of deductive reasoning. But I must disagree with Hitchock who writes (130), "What is new too . . . is the skepticism about the value of formal logic as a tool for analyzing and evaluating natural-language arguments." This was precisely the view, in the $19^{\text {th }}$ century, of the independent co-founders of modern formal logic; just as it was the view, in the $17^{\text {th }}$ century, of the Port Royal logicians and of John Locke, contra the syllogistic.

Something important turns on the present point, and it brings forth some rather harsh criticism of informal logic. Informal logicians have allowed themselves to be derisive towards modern logic for failing to bring off what in fact it never set out to achieve, a confusion which arose from the ignorance of authors of elementary textbooks and those who teach from them. Properly understood, the complaints of informal logicians should have been directed to those who were guilty of the confusion, not to the creators of modern logic. So the grumpiness of some of those commentators who bridle at the confusion is understandable. ${ }^{10}$

\subsection{Formal Logic: A Bootstrapping Problem}

No doubt some readers will object that 1 have overlooked the rôle of canonical notation in formal logic." The phrase is Quine's and it denotes an alternative to the Fregean (and Carnapian) notion of artificial languages. How much of an alternative I can only sketch here.

A canonical notation is the net result of a set of schematization procedures for a fragment of an actual language-a "colloquial language", in Tarski's words. These procedures are also (misleadingly) called the "translation" rules from colloquial language-structures to their counterparts in canonical notation. The question, "Why translate this way rather than that?" has a principled answer. The translation of choice is the set of transformations that already constitute the canonical regimentation of that natural language-structure. In the approach I associate with Frege and Carnap, artificial languages are built by fiat from the theorist's stipulations. They are original languages, not transformations of existing ones. This makes the whole business of mapping, e.g., ordinary mathematical German into the logician's artificial language a somewhat more difficult thing to understand. A further difference between artificial languages and canonical languages pertains to atomic formulas, open and closed. In artificial languages such expressions are uninterpreted. In canonical notation they are allowed their natural language interpretations, but, for technical reasons, these don't influence the interpretations of compound expressions. ${ }^{12}$ They are atomic interpretations that "don't matter". So it is distinc- 
tion without a (relevant) difference. For the purpose of tracking the target properties of logic, simple sentences of natural languages have no semantic context.

A language in canonical notation is a sublanguage of a natural language purged of vagueness and of syntactic constructions which induce intensionality; and supplemented by neologisms as needed. Again, vagueness is leeched out by suppressing the interpretation of all categories of expression save for the logical particles. Quine calls the set of procedures that canonize a fragment of natural language its Standard Grammar. Standard Grammar is a branch of linguistics, itself a natural science. In as much as the target properties of logic are distributed over the structures of Standard Grammar, Quine can claim a naturalistic provenance for logic, as Dewey had done before him. ${ }^{13}$ (And here too, en passant, informal logicians have missed the boat. Informal logic is not made distinctive in relation to formal logic by its enthusiasm for naturalism. $)^{14}$ The second point to take note of is that in Methods of Logic, Quine thinks that a serviceable notion of logical form can be got out of canonical notation. ${ }^{15}$ For any argument constructable in such a sublanguage or language-fragment there is a schematization of it in canonical notation, and this in turn may be identified as the original argument's logical form (in the logical system in question). Schematization procedures ${ }^{16}$ are designed to have what I call the backwards reflection property with respect to the theory's target concepts. If, for example, the logical form of a natural language argument is valid, so too is the argument itself. (Similarly for other target properties such as inconsistency and logical truth). Informal logicians have been known to heap considerable scorn on the very idea of backwards reflection. They are right in sensing difficulties, but they look for them in the wrong place. Perhaps the leading example of a misplaced fuss is the one made about material "implication". Critics are right to say that material "implication" isn't implication, but they are wrong in thinking that this compromises the usual schematization procedures and spells the death of backwards reflection. Some people are encouraged in these confusions by the unfortunate claims made so often in logic textbooks-Methods is a notable exceptionbut they are confusions all the same.

Peirce saw very clearly that schematization procedures are not part of logic proper but rather of linguistics. ${ }^{17}$ This is also Quine's view, but with a difference. The difference is that Quine' attaches to his regimentation policies a strong philosophical motivation. Natural languages tend to have phrase-structure grammars. Phrase-structure grammars have rather weak semantics. ${ }^{18}$ Regimentation is a complex transformation of a natural language. The transformed language has a categorial grammar. Standard Grammar is categorial. Categorial grammars have a rich semantics-model theory, essentially. Model theory delivers a strong and mature theory of truth (Tarski's essentially). It is true, and important, that the mapping that takes a language with a phrase-structure grammar into a language with a categorial grammar does not preserve the structure of the original grammar. This puts it in doubt that meaning is preserved between the original and the regimented 
language. For many people this is a serious blow to regimentation. For Quine it is a virtue. He has long held that meanings are incapable of heavy lifting in science and philosophy. All that he needs or wants from semantics is a theory of truth, which a categorial grammar makes robustly available, but becomes available only after regimentation.

Even if Quine is right about the backwards reflectivity of such procedures, they would hold for only judiciously selected subsets of English, in fact those very subsets that gives the assertion of backwards reflection the best chance of being true. In a word, they are fragments of English which have the best chance of dancing to a categorial grammar. So Quine's Methods of Logic gives no encouragement to the claim that first order logic can be seen as a theory of argument for whole natural languages; since theirs is a phrase-structure grammar.

We have noted the impoverishment of the object languages of formal logic. Consider the classical system $P$ of propositional logic. The sentences of $P$ are contentless; they fail to express a complete thought, as the grammar books used to say. Even so, $P$ has the resources to support definitions of and to discern the presence or absence of all the target properties of propositional logic. These properties are

- the property of being a wff of $P$

- the property of being a tautology of $P$

- the property of being a contingent wff of $P$

- the property of being a contradictory wff of $P$

- the property of being a valid argument of $P$

- the property of being an invalid argument of $P$

- the property of being a consistent set of sentences of $P$

- the property of being an inconsistent set of sentences of $P$

Each of these properties is decidable in $P$. For each of them there exists a (1) mechanical, (2) infallible and (3) finite procedure which enables us to determine with regard to any arbitrarily selected object whether or not it has the property in question.

It is certainly rather remarkable that something with so little expressive power should be able, like $P$, to have such command over the target properties of logic. Even so, systems like $P$ stand open to a serious objection. It is that sense we neither do nor can do our thinking or our arguing in a language such as that of $P$, the theory of inference and of argument that $P$ develops is useless.

Can this objection be met? It can, at least up to a point. The reason for this is twofold.

First. It is possible to formalize English arguments in $P$.

Second. Formalization has the backwards reflection property, as we have said. 
The first point is one any teacher of formal logic is already acquainted with. The second needs some explaining.

Backwards Reflection. Suppose that $T$ is a target property of our logic (e.g.,validity). Let $E$ be an argument in English. Applying the schematization rules of $P$ to this English argument $E$ gives its logical form, $F$, in $P$. Then the schematization that produces the logical form of $E$ in $P$ has the backwards reflection property with regard to $T$ (e.g., validity). If $F$ is valid, so too is $E$.

This really is quite remarkable. It shows that formalizing a content $f u l$ argument in English as a contentless argument in $P$ allows us to determine with certainty whether the English argument is valid.

What a wonderful thing formalization is, or so some people will say. Others will say that it is too good to be true! To see what their reservation comes down to, it is helpful to remind ourselves that there are constraints on what can be inputs to our formalization rules. For example, we are not allowed to apply these rules to interrogative sentences of English, nor are we allowed to formalize molecular sentences of English as atomic sentences of $P$. And we are not permitted to formalize any connective of English other than 'not', 'or', 'and', 'if . . then ...', and 'if and only if', and those that can be defined in terms of these connectives.

Consider in particular the rule that only simple sentences of English can be mapped on to atomic sentences of $P$. Are there any other constraints on this atomic rule? Consider the argument

1. If Sue has been awarded the first university degree, then Sue is a bachelor.

2. If Sue is a bachelor then Sue is an unmarried man.

3. Therefore, If Sue has been awarded the first university degree, then she is an unmarried man.

If we now apply the formalization rules to this argument, we see that its logical form in $P$ is
1.* If $p$ then $q$
2.* If $q$ then $r$
3.* Therefore if $p$ then $r$.

This matters. Here is an English argument with a valid logical form in $P$. But the English argument is invalid. We wanted validity to have the backwards reflection property, but the present example shows that it doesn't.

We can solve this problem by noticing that our English argument equivocates on the ambiguous term "bachelor". In premiss (1) it means one thing, and in premiss (2), it means something quite different. This gives us a way out of our difficulty. We can impose upon the formalization of English sentences the Disambiguation Rule. The rules says that for any expression of English which has 
more than one meaning, its different meanings must be mapped on to different expressions of $P$. Applying this rule to our present example we see that the correct logical form of our English argument is

1. If $p$ then $q$

2. If $s$ then $r$

3. Therefore, if $p$ then $r$.

This gives us the desired result. The logical form is invalid. So it would appear that when we add the Disambiguation Rule to our rules of formalization, that validity does indeed have the backwards reflection property; for we no longer have an argument, which is valid in $P$ but invalid in English.

What, then, about invalidity? Does it too have the backwards reflection property? Consider the following argument.

1. The shirt is red.

2. Therefore, the shirt is coloured.

The premiss is a simple sentence of English which entails the conclusion, also a simple sentence of English. Its logical form in $P$ is

\section{$1 .^{*} p$ \\ 2.* Therefore, $q$}

which is invalid.

Here is a second case.

a) The figure is a triangle

b) The figure is a circle

This is an inconsistent set of sentences in English. But the logical form of this set in $P$ is $\{p, q\}$, and $\{p, q\}$ is a consistent set.

In the first case, invalidity fails to have the backwards reflection property. In the second case, consistency fails to have the backwards reflection property. But we want all our target properties to satisfy the backwards reflection condition. We want this because we want $P$ to be useful in the appraisal of real-life reasoning and real-life argument.

As it happens, we can recover the backwards reflection property with regard to invalidity and consistency if we agree to impose a further condition on our formalization rules. It is called the Logical Inertia Rule, which says that

Simple sentences of English to which the schematization rules apply may not either entail one another or be inconsistent with one another. In other words, the simple sentences that are inputs to the formalization mechanism of $P$ must be logically inert.

It seems, then, that we have recovered the backwards reflection of validity by imposing the Disambiguation Rule, and likewise that we have recovered the backwards reflection of invalidity and inconsistency by imposing the Logical Inertia Rule. Even so, there is a cost to these recoveries. 
Let us deal first with the cost of imposing the Logical Inertia Rule. This requires us to be able to recognize entailment and inconsistencies between simple English sentences in a reflective and disciplined way. This is equivalent to saying that we must have a theory of entailment and inconsistency for English. But this is what our formalization rules were supposed to provide. $P$ would analyze the properties of entailment and consistency, and our formalization rules would reflect them back into English. So $P$ together with the formalization rules would be a theory of entailment and consistency for English. But, as we now see, we can run the formalization rules until we have a theory of entailment and consistency for English. And we don't have a theory of entailment and consistency for English until we've executed the formalization rules. So we have a bootstrapping problem.

Faced with this kind of difficulty, most logicians have, in effect, withdrawn the Logical Inertia Rule and, in so doing, have abandoned the hope that invalidity and consistency would have the backwards reflection property.

The Disambiguation Rule is a different matter. If it goes then we loose the backwards reflection of validity. So the question now is whether we are able to apply this rule in a principled way. The answer is no. We do not yet have a theory that permits us to recognize ambiguity in the general case. (In fact, a good many philosophical problems have turned out to have resulted from undetected ambiguities.) This leaves us with Hobson's Choice. Either we can give up on the backwards reflection of validity or we can try to apply the Disambiguation Rule in other than a principled way, that is to say, intuitively. Most logicians opt, in effect, for the second option. (I shall return to this point.)

\subsection{Fit Work for Informal Logic}

It would be wrong to leave the impression that informal logic derives entirely from misconceptions about what logic is for and what it is capable of. Formal logic-in the form of mediaeval variations of the theory of syllogisms- has been the subject of hostile comment since the Renaissance. In France, under Descartes' influence, the Port Royal logicians thought (rightly) that the syllogistic could play only a small part in an overall account of the art of thinking, whether in science or everyday affairs. In England, a like skepticism derives from Bacon, and is present in Locke and a strong motivator of Mill's A System of Logic. It is interesting that while Arnauld, Nicole and Locke thought that deductive logic was perfectly all right in its place, Mill thought that it was a satisfactory complete theory of reasoning. By this he meant that for every bit of good (or bad) reasoning there existed a paraphrase in the syllogistic which matched the original in goodness (or badness). Mill also thought that the syllogistic schematization of these pieces of reasoning were invariably imperspicous; that is, they obscured their deep structures or, as we ourselves might say, their true logical grammar. 
Mill also held the opposite of Peirce's view that there could be no logic of vital affairs. Not only did Mill think that a logic of ordinary reasoning was possible, he thought that this same logic was the logic of science (a respect in which his connection with present-day informal logic is called into question perhaps).

There is also historical precedent for the claim of informal logicians that formal logic is useless, that as a sharpener-up of real-life argument and reasoning it is a total failure. This indeed was precisely Locke's opinion too. And there is historical precedent for the acrimony which occasionally shows itself in the relations between formal and informal logicians. We find it in Frege's discussion, in the Grundlagen, of Mill's logic. To say that it was a hatchet job would be an understatement. Frege's account of Mill is so riddled with errors and inaccuracies as to qualify as a grand, a total sophisticus elenchus. How ironic that today it is often informal logicians who display the same scholarly tawdriness in their excoriations of the logic of which Frege, of all people, was co-inventor.

Informal logicians are right to say that modern formal logic is not up to the demands of a theory of argument of every stripe that argument comes in. It is open to question whether modern logic has a rôle to play in such theories that is anywhere close to the centrality that Aristotle claimed for the logic of syllogisms (though I myself doubt it). If the theory of argument, or the theory of inference, could be said to possess core logics, the best that I see for classical logic is as special cases of the core logics, in much the way that classical logic is seen to be a limiting case of quantum logic or of dialethic, or strongly paraconsistent, logic.

There remain the questions not only of what informal logic $i s$, but rather more importantly of what we want it to do for us. I suggest that these questions be answered in reverse order. What informal logic is will turn out to be a function (loosely speaking) of the purposes for which it was designed.

If informal logicians are agreed on anything positive, it is surely that informal logic should be, or should be a large part of, a theory of argument. (There is, I think, a smaller majority who think that it should also be a theory or a large part of a theory of deductive inference; but we are here sticking with argument). Argument is a plural concept. Lots of different kinds of things are arguments. So, if we were to set ourselves the task of sketching a modus operandi for the would-be informal logician, the first task we would ask him to perform is:

$T_{1}$ : Identify the kind or kinds of argument he intends to theorize about. Then,

$\mathrm{T}_{2}$ : Supposing his interest to be confined to arguments of the $\mathrm{K}$-sort, for some kind $\mathrm{K}$, announce his theoretical designs upon them.

$\mathrm{T}_{3}$ : Motivate those objectives. (Why is it desirable that they be pursued?)

As an example, let us say that our theorist opted for arguments of the sort that Freeman discusses in these pages (118-119). Suppose, with him, that the theorist has designs on the property of argument-cogency, and that his objective is moti- 
vated by his conviction that cogency hasn't yet attracted a satisfactory theory. How does he proceed? A partial, but I think central, answer is that it is desirable that the theorist satisfy the following adequacy conditions.

$A_{1}$ : The theory should specify conditions on argument cogency. It should try to justify the choice of those conditions.

$\mathrm{A}_{2}$ : Suppose, for the sake of discussion, that the conditions in question are Freeman's own conditions of relevance, groundedness and acceptability. Then the theory should give an account of embedded properties of relevance, grounding, and acceptability. Another way of saying this is that the theory should contain subtheories of these properties. $^{19} 20$

If tasks $T_{1}$ to $T_{3}$ could be accomplished satisfactorily and if adequacy conditions $A_{1}$ and $A_{2}$ were fulfilled, some people might suppose that the resultant account would qualify as informal logic. The supposition would be premature. For suppose that our interest were in reductio arguments. The story of such arguments is fairly well-known and not much contested. ${ }^{21}$ Suppose that we managed to perform $T_{1}$ to $T_{3}$ and to satisfy $A_{1}$ and $A_{2}$. What point would there be in holding that our reductio theory was a contribution to informal logic rather than to logic? Or suppose that our theoretical designs fell upon collective bargaining arguments and that the target property were "good faith" moves in such arguments. If our theory is any good, it would honour the fact that if a party's opening offer is also his final offer, this constitutes a failure to argue in good faith. Imagine that here too $T_{1}-T_{3}$ were satisfactorily performed and $A_{1}$ and $A_{2}$ were satisfied. What point would there be in characterizing the theory as informal logic, or indeed as logic ?

\subsection{Logic and Informal Logic}

If we look fondly on terms such as "logic" and "informal logic" scampering around in our favourite metatheory of argument, we would do well to find some useful work for them to do. In the context of a theory of argument, one possibility is to settle for a decision to reserve the generic name of logic for a theory or subtheory whose target properties are either properties of propositions (e.g. logical truth) or sets of propositions (e.g. consistency), as well as the properties one encounters in the attendant metatheory (e.g., decidability). Target properties that fell beyond the reach of this test would not be in the province of logic. A virtue of the this suggestion is that it takes care of the formal-informal divide in a fairly natural way, flexibly, and free of unnecessary essentialism (if I may put it that way). Let $\left\{P_{1}, \ldots\right.$, $P_{n}$ \} be the set of target properties of the logical subtheory of a theory of argument of the sort we have been discussing. Then, if the formal-informal divide is definable for this set, it will partition into non-empty proper subsets of $P_{i}$ and $P_{j}$. Let the $P_{j}$ be target properties of classical logic (i.e., first-order quantification theory) or direct rivals of them in regard to those properties (e.g., higher-order quantification 
theory, intuitionism, or relevant logic). Then, although the theory of argument in which they are embedded may require some further qualification of those properties, that part of the logical subtheory that deals with them is formal logic. Subject to similar caveats, that part of the theory dealing with the $P_{j}$ is informal logic. 1 should quickly explain these caveats. We would expect properties such as consistency and implication to fall within the formal logic component of a theory of argument. Even so, given the particularities of real-life argument, the theory might adapt or customize their account accordingly; and so, for example, it might crimp the generality of the adjunction law, or give up the monotonicity of implication. Similarly, I expect that we would find premiss-acceptability to fall within the informal logic subtheory of a theory of argument. It could be that the theory draws upon accounts of acceptability from elsewhere (decision theory, possibly). We could expect the borrowing might need to be adapted to the peculiarities of actual arguments, by modifying the theory's "perfect information" assumption, to take just one example.

Of course, there is also a more latitudinarian way of understanding logic. According to this second possibility, a logic is a formal idealized description of the behaviour of a logical agent. Such a view requires elucidation of the key concepts of formality, ideality and agency, an interesting task for which I lack space here. ${ }^{22}$ However, it is fairly easy to see that the formality involved in this approach cannot be restricted to matters of logical form. What makes this so is that logical form is a linguistic notion, and logic in the present sense formally describes logical agents. Ideality, too, bears on this matter. Idealized descriptions of what people do are (in part) misdescriptions of what they actually do. Even so, idealization is permissible to the extent that actual behaviour is an approximation of ideal behaviour, or behaviour in an ideal model, and the approximation relation itself is exposed to a reasonable measure of theoretical elucidation. Agency in the model will in turn mimic the actual behaviour of cognitive agents, subject to the requisite constraints or idealizations. Even so slight a sketch as this gives us a conception of logic that easily subsumes anything that currently passes for informal logic, and it, too, allows for a principled distinction between informal and formal logic. Formal logic is a theory of logical forms; and informal logic is all the rest. ${ }^{23}$

There may well be reasons to prefer the first, rather narrower, conception of logic to the present, broader conception. I myself favour the more latitudinarian approach, but it is not something to stake one's life on.

\subsection{A Central Problem for Informal Logic}

Whichever conception of logic we are drawn to, serious problems remain. As we saw, no formal logic is applicable to natural language structures save those that are regulated as inputs by theories of ambiguity, implication and inconsistency. These theories allow us to judge when natural language items are admissible as inputs to 
the schematiziation rules which produce the logical forms of those inputs. Such theories are theories of ambiguity, implication and inconsistency for natural languages. The irony is unmistakable. Formal logicians are drawn to the view that natural language accounts of ambiguity, implication and inconsistencies must depend on formal theories of these same things. But you can't get a formal treatment of these properties in natural language contexts without the aid of informal theories of ambiguity, implication and inconsistency. But if such theories were available, what would be the point of having formal theories of the same things? Point to the informalist. A formal logic for natural language arguments is parasitic on an informal logic. But-point to the formalist-there is no stable consensus about what these informal theories should look like.

A first task, therefore, of informal logic is production of supportable theories of ambiguity, implication and inconsistency for natural languages. Some will see this as work for linguistics; others as work for informal logic. It hardly matters. It is the work that is important.

\section{Philosophy}

\section{I Contra Philosophical Exclusivity}

Historically and administratively logic has been a part of philosophy for a long time. Not even its more recent flourishing in Departments of Computer Science and Mathematics has damaged this ancient affiliation. It comes as no surprise, therefore, that when a researcher does work that he classifies as informal logic, more often than not he is a philosopher. That alone makes informal logic part of philosophy as any operational conception of philosophy the work that philosophers do.

It would seem that Hitchcock and Freeman see informal logic as more substantially linked to and deeply embedded in philosophy than any mere honorific could provide. Hitchcock sees informal logic as a sub-discipline of philosophy. I demur from this view if the subsumption is intended exclusively. If we agree that informal logic is defined by the Johnson and Blair questions of 1978 (see Hitchcock, 129-130), then some are questions primarily for philosophy, while others roam more freely (as indicated by the parenthesized clauses). Among these latter are:

- What is the nature of argument? (Rhetoric; linguistics; discourse analysis; conversation analysis; law)

- What is the nature of fallacy? (All the above.)

- Are the validity/soundness criteria of the evaluation of arguments inappropriate or outmoded? (All the above, plus social psychology.)

- If so, what should replace them? (All the above.) 
- Can principles be formulated that assign responsibilities of give-andtake argumentation? (Debating; law.)

- How does the context of argumentation affect meaning and interpretation? (Psycholinguistics; computer science.)

Since answers to the Johnson and Blair questions are at least a large part of what passes for informal logic, and since they are not by any means reserved for philosophers, it now strikes me that, contrary to initial appearances, informal logic's place in philosophy is for Hitchock rather more contingent and honorific than substantial. But the same cannot be said for Freeman.

As Freeman sees it (120), unlike the key concepts of formal deductive logic (e.g., validity and logical truth) which can be defined "without significant philosophical enquiry", the key concepts of informal logic (viz. acceptability, relevance and adequacy of ground) are or ought to be matters "for philosophical attention, in particular, for epistemology." ${ }^{24}$ How so?

The main link is the concept of justification. An argument is cogent if and to the extent that its premisses justify believing its conclusion and to the extent that the premisses themselves are justifiably believable. But justification is an inherently epistemological concept. So, informal logic is intrinsically linked to epistemology. I find this doubtful in two ways. One is that there are theories of knowledge that have nothing to say about justification (e.g., certain reliabilist theories ${ }^{25}$ ). The other is that even if there is a concept of justification that is intrinsic to epistemology, it does not follow, and in any event seems not to be true, that this is the sole concept of justification appropriate to a theory of argument. A theory of argument that investigated negotiation arguments would have occasion to say something about when it is justified to put one's final offer on the table, but this hasnothing to do with epistemology. Similarly, a dialogue logic might pronounce on when it is justifiable for one party to attribute a position to the other party, but this too has nothing to do with epistemology. It may be time that an epistemological notion of justification is inextricably bound up with the factors of premiss-acceptability, premiss-conclusion relevance and adequacy of the groundedness of conclusions in premisses; but, as I have been attempting to show, if informal logic is the study of arguments on the hoof, then there will be cases galore in which arguments will give the theorist no purchase for this trio of properties. So I conclude that Freeman has not (yet) made good on his claim that informal logic is inherently part of epistemology.

What, then, do we make of the following argument? Freeman points out (122) that

1. Every argument has a basic premiss.

2. Every basic premiss is in principle the subject of an argument. ${ }^{26}$

For Freeman, these propositions (especially the first) establish that informal logic is foundationalist, and he thinks that the foundationalism of informal logic is the same thing that one finds in what he calls "common sense foundationalism" in 
epistemology. Thus $\mathrm{P}$ is a properly basic propositions for me if and only if "there is a presumption from my point of view that my cognitive mechanisms which generated this belief are generally reliable and functioning properly, in a normal environment, with a view to producing true beliefs" (123).

So, then, "we might [in turn] explicate premiss acceptability as proper basicality understood according to common sense foundationalism" (124). But here, too, I admit to some doubts. From the point of view of the arguer, the approach is too liberal. Virtually all his premisses would qualify as properly basic just by virtue of the arguer believing them and having no reason to believe that his belief is abnormal. In other words, it will be an arguer's default position that his premisses are such as to satisfy the definition of proper basicality. On the other hand, for anyone else, an arguer's proper basicality is not a matter for the external evaluator to judge, since it obtains or not strictly on the basis of what the arguer sincerely believes. One might think that I have misread the qualification "has not reason to believe that his cognitive mechanisms are defective or that his situation is abnormal." If this doesn't mean "doesn't in fact think ..." but means instead "there is objectively no reason to think", then judgements of proper basicality, for both arguer and evaluator, cease to be made in accordance with a criterion to which they have effective and routine access.

My own view is that given the shaky state of epistemology in general, the less that informal logic must have to do with epistemology, the better. But if we must have some epistemology to leaven our informal logic, I myself would be more disposed to Everitt and Fisher's adaptation of Quine's naturalism to argumentative contexts. ${ }^{27}$

\subsection{A Further Adequacy Condition}

Even so, perhaps Freeman is right, never mind my own doubts. It strikes me in any case that premisses never justify conclusions. It is people who justify, and it is actions plans and policies upon which justification bears. In its use as a propositional relation, "justification" is a technical term in whose metaphorical character all connection with epistemology and ethics is lost or at least made non-obvious. Whether or not there is a deep connection with philosophy; it appears that we can cite a third adequacy condition on a theory of argument, and then some people may see it as a philosophical condition.

$A_{3}$. A theory of argument should seek to determine conditions under which the theory's target properties and the conditions in which they are embedded are recognizable.

A condition or a property is recognizable when and to the extent that an arbitrarily competent and appropriately situated subject can know whether the condition is satisfied and whether the property is instantiated. In extremis, recognizability is decidability, which is too much to hope for in general, as we know. Perhaps we 
could agree that if anything is an exercise in epistemology, it is plotting a strategy which aims at satisfying $A_{3}$ It is a far from easy exercise. (I want to say this with some emphasis. It is the central methodological problem for the Humanities). Perhaps it is not surprising that my fellow symposiasts do not in these pages acknowledge $\mathrm{A}_{3}$. It may strike us that Freeman comes closest to doing so, what with his call for an epistemological theory of justification. In fact, it is precisely $A_{3}$ that the type of epistemological theory which Freeman envisages fails to satisfy.

Among present-day informal logicians, $A_{2}$, the requirement that properties embedded in conditions on argument-cogency themselves be the target of subtheories, is most explicitly recognized by Weinstein. To be sure, when we need only examine the research record of the others we see that at least some of their work honours the spirit of $\mathrm{A}_{2}$ more or less strongly or weakly. Hitchcock on relevance comes again to mind on the strong side, as does the same author on material validity. But nobody, I think, has a better methodological appreciation of $\mathrm{A}_{2}$ than Weinstein. He is someone who sees the utter importance of the subtheory to the overall design of a theory of argument.

If $A_{3}$ links the theory of argument to philosophy, it is not a distinctive linkage; it doesn't differentiate theories of argument from theories of other things. All theories are subject to $A_{3}$. The extent to which philosophy is involved beyond what $A_{3}$ requires will turn on the theorist's way of satisfying $A_{1}$, which in turn generates the target properties of the subtheories called for by $A_{2}$. Seen in Weinstein's way, and lately also in Johnson's, truth is a condition on argument-cogency and thus is subject (so I say) to $\mathrm{A}_{2}$-level theoretical investigation. What makes me think that Weinstein has the right appreciation of $A_{2}$ is that he has actually produced the subtheory of truth, whereas Johnson has not yet done so. ${ }^{28}$

\subsection{Toulmanization and Dialectification}

$\mathrm{A}_{3}$ is perhaps the most economical way of marking a precise distinction between formal and informal logic, according to our first conception of logic of pages ago. Formal logic could be seen as handling the $A_{3}$-question using in-house resources and methods. Put somewhat oversimply, it would fall to formal logic itself to ascertain whether or not a given instance of its structures satisfies conditions defining a target property. These are its proof procedures and (where they exist) decision procedures. Informal logic has no analogous in-house strategies. It is possible to see two ways in which an informal logician might get on with the business imposed on him. One is fairly explicit in the actual practice of some informal logicians. The other is surprisingly tacit. On the first of these approaches, the theorist Toulmanizes the $\mathrm{A}_{3}$-project. On the second, he dialectifies it. Toulmanization transfers the burden of $\mathrm{A}_{3}$ to the methodologies of the discipline in which the argument in question has been constructed, and it also takes supplementary guidance, if any, from whatever formal logic may have to say about it. 
Perhaps the leading virtue of Toulmanization is economic. It is a strikingly efficient way of generating argument criticism. But its virtue is also something of a liability, for informal logic would now seem to have no critical capacity of its own. $A_{3}$ commands the theorist to furnish ways of determining whether an argument satisfies the Freeman-set (relevance, acceptability, groundedness\} or the JohnsonBlair-set \{relevance, acceptability, sufficiency\}. When this requirement is Toulmanized, the argument in question is sent to its home discipline if it has oneto physical chemistry in Weinstein's favourite example. Whether the premisses are acceptable, whether they bear relevantly upon the issue at hand, and whether they give adequate support to the conclusion, all these are questions for the physical chemist. Now if Toulmanization is considered an appropriate general strategy, there is no work for informal logic to do short of satisfying $A_{1}$ and $A_{2}$. Doing the business of $A_{1}$ is largely definitional, and the business of $A_{2}$, the importantly analytical business, has by an large been ignored by informal logicians. If this is right, it goes some substantial way toward explaining why (to the extent that it is true) informal logic is ignored by establishment philosophy and establishment logic.

The second way of proceeding with $\mathrm{A}_{3}$ repairs an deficiency of Toulmanization. It is this: A great many arguments are not disciplinarily based. They are about everyday things concerning which there are no experts or, if there are, are such as not to require their intervention. They are arguments which lie within a general competence enriched by the contingencies of shared experience. This leaves these arguments oddly positioned. Either they don't admit of criticism or they do. But if they do, criticism is what the ordinarily competent real-life thinker happens to think of it.

Dialectification erases this distinction between disciplinarily expert- and ordinary guy-criticism. Let $\mathrm{K}_{1}, \ldots, \mathrm{K}_{\mathrm{n}}$ be the conditions under which an argument is cogent. $A_{3}$ bids the theorist to make the $K_{i}$ recognizable. Dialectification offers a way of proceeding by forwarding the $K_{i}$ to a generalized methodology for conflict resolution. To take pragma-dialectics as an example, the question of whether an argument satisfies a pragma-dialectical rule can it self be subject to a process of dispute resolution governed by those same rules. Thus the question of whether an argument satisfies a condition $\mathrm{K}_{\mathrm{i}}$ would be settled in a "rational discussion" governed by those rules which terminates in agreement that the argument does (or does not) satisfy $\mathrm{K}_{i}$. As mentioned, there is in actual theoretical practice little express recognition of $\mathrm{A}_{3}$-satisfaction through dialectification. But there can be little doubt that its applicability is a fairly strict (even if tacit) consequence of the dialectical approach to arguments generally.

By and large, then, informal logic has shown little capacity for doing the business of $A_{3}$. In this informal logic stands in rather stark contrast to formal logic. How embarrassing is this? If we find ourselves thinking that a theory of argument that lacks a critical apparatus is a hobbled thing at best, then this is bad news for informal logic. On the other hand, on the principle that one cannot get blood from a turnip, it may be that $A_{3}$ is an unrealistic condition to impose on the informal 
logician. But if so, we need a limitation theorem; the informal logician must establish $\mathrm{A}_{3}$ 's inapplicability to what he does.

I note, however, that these objections largely vanish if we opt for our second, more latitudinarian conception of logic, in which a logic is a principled description of what logical agents do. So understood, both Toulmanization and dialectification are manoeuvres that fall well within the ambit of informal logic.

A case can be made that informal logic lies closest to the bosom of philosophy in the work of writers such as Finocchiaro (Galileo and the Art of Reasoning, especially in Chapters 2 and 16, less so in Chapter 5), and Fisher (The Logic of Real Arguments). I see these works as continuous with the Commentaries of times gone by. They are detailed interpretations and schematizations of a series, often an entire system, of complex arguments. The aim of the commentator to unify, clarify, precisify and fill in the missing bits. It is also his function to elucidate the manner in which the author has made his case and to subject those methods to a critical scrutiny appropriate to the author's time and subject. Of course there are clear differences between systematic philosophical commentary and informal logic, but in the cases under review there is an impressive overlap. ${ }^{29}$

\subsection{Ordinariness and Everydayness}

Some of the best work in the theory of argument is rather difficult. Informal logicians sometimes show a jaundiced eye to difficulty. Fisher finds Freeman wanting on this score. He says that Freeman's "wonderfully insightful theory . . . in Dialectics and the Macrostructure of Argument is flawed; it is so complex that it is frequently not applicable to real reasoning by the ordinary reasoner" (110). If Fisher is right about this (and indeed it is far from being his view alone), it transmits a strong procedural message to the theorist; and it all but puts people like Weinstein (and perhaps the present author, too) out of business as informal logicians. There is certainly nothing wrong in (a) seeking accounts of arguments that ordinary people are actually capable of making without specific tuition; and there is nothing wrong in (b) hoping for theories which the ordinary person can profitably apply without tuition, save that provided by the theory itself. (Such theories are what Walton and I once characterized as "manuals of self-help for the argumentatively insecure".) But there is nothing to recommend the converse implication according to which theories that fulfill (b) are in general theories that more naturally "suit" the untutored behaviour of ordinary folk. Even very stupid ordinary folk acquire untutoredly the habit of competent speech; but as any linguist will attest, there isn't the slightest prospect of a non-complex theory for such behaviour.

In his "Reconciliation of Formal and Informal Logic", ${ }^{30}$ Copi tells of some correspondence he had with the present writer on the analysis of ad baculum arguments. Generous to a fault in his praise of the analysis, Copi nevertheless had 
a criticism. My analysis would prove too complicated to teach to first year college and university students. In this Copi and I disagree, but this is of no mind. Copi could be quite right about his pedagogical reservations, but without some rather hefty supplementary argument, no one (certainly not Copi) would accept that the upper bound on a theory's admissible complexity is what a freshman class can be got to swallow. Johnson and Blair also plump for the "everyday" (94-95), as does Freeman for "arguments of the polis" (118-119), and they do so in a way that makes me suspect them of what I see as Fisher's mistake. Van Eemeren and Grootendorst, indifferent to the ambiguity of it, also concentrate on "ordinary language users"; but they are not in fact making this mistake, even though it may seem that they are."

Still less is there reason to equate real arguments with ordinary arguments if by "ordinary" we mean untutored or something close, as Fisher's own The Logic of Real Arguments makes clear. My $\mathrm{T}_{1}$ tells the theorist to pick his argument type; $\mathrm{T}_{2}$ asks him to confess his theoretical designs; and $T_{3}$ bids him to motivate their choice. There is nothing in this that precludes simple theories about commonplace events. But there can be no question of an intrinsic preference for the easy and the everyday, never mind that this is what many "theorists" appear to believe. This has a bearing on the linkage with philosophy. Philosophy is built for the complex, the difficult and the uncommon. If informal logic were inherently a matter of simple theories about everyday things, there would be (apart from $\mathrm{A}_{3}$ ) little occasion for nontrivial philosophical engagement. Contraposition fails this conditional. Even though informal logic is not confined to the simple and easy, it does not follow that apart from $\mathrm{A}_{3}$ philosophy has a substantive role in the theory of argument. But the door is left open.

Bearing on the present question is the suggestion of Johnson and Blair (102) that developments in fuzzy logic may prove helpful to the informal logician. It is useful to compare fuzzylogic with ordinary probability theory. Probability theory is the arithmetic of the real line constrained by special aleatory axioms. Fuzzy logic is also a kind of probability theory, but a theory of considerably more mathematical and axiomatic complexity than the standard account. In an alternative approach, fuzzy logic is fuzzy set theory plus something else. Fuzzy set theory models Kukasiewicz's indenumerably many-valued logic. Fuzzy logic is a nonconservative extension of this model. It is got by adding fuzzy truth values, which in turn are fuzzy subsets of the set of values of the many-valued logic. Thus it is provided that in fuzzy logic truth comes in degrees. Either way, fuzzy logic purports to model the human capacity for reasoning with inexact concepts. It does this by exploring the assumption that when we argue in inexact terms and draw inferences in imprecise vocabularies, we actually (or ideally) make computations abouttake the measure of-the embedded imprecisions. My own view is that this is the last thing that we do, and indeed that we do the opposite. That is, we omit taking the measure of inexactitude, and we do so for the sake of cognitive economy. I don't doubt the human being's capacity for an appropriately detailed computa- 
tional command of even radical fuzziness, but I do doubt that it could be other than a subcortical achievement. Once consciousness enters the picture, representation becomes a dominant factor, and a linear one. But real-time linear treatments of highly complex phenomena are inordinately inefficient. So I conjecture that beings like us are hardwired (or something close) for hard-edged, highly bimodal conscious experience. ${ }^{32}$ In this I could very easily be wrong, but one thing is clear. If fuzzy logic does have a place in informal logic, then goodbye forever to any idea that informal logic should be neither difficult nor complex. ${ }^{33}$

\subsection{Fallacy Theory}

Over the years there has been a question about the place of fallacy theory in informal logic. Unless I am mistaken, Hitchcock resists the inclusion on pedagogical grounds, ${ }^{34}$ Freeman for rather more theoretical reasons, perhaps, and Fisher, too, possibly in the spirit of Finocchiaro's reservations. ${ }^{35}$ Nor are fallacies anywhere to be seen in the Weinstein research programme. Johnson and Blair are differently minded, and lean toward a welcoming ecumenism. I hold a twofold view of this question. If we stick with the traditional generic idea of fallacy as an argument or a move in an argument which appears to be all right in a certain way but isn't in fact all right in that way, then it falls to the theory of argument itself to determine whether this concept is empty or non-empty, and if non-empty, whether it can be involved in the discharge of tasks $T_{1}$ and $T_{2}$. Let us suppose that fallacies are indeed theoretically scrutable and theoretically well-motivated. Whether they fall within the logical ambit of a theory of argument, and, if so, within the formal or informal sub-ambits, will be determined one by one by the theory itself, and with an exactitude and a determinancy that matches the exactitude and determinacy of those very distinctions in the master theory.

One reason to like the traditional conception of fallacies, and the historical accumulation I have called The Gang of Eighteen (which by and large are the fallacies discussed in most of the more or less standard texts), is that a clear answer is possible to the question of the linkage between informal logic and philosophy. The short answer is that most of the Gang of Eighteen are philosophical research programmes in their own right. ${ }^{36}$ What chance is there of having theoretically mature accounts of, for example, inductive fallacies such as hasty generalization, without some substantial headway having been made with issues such as the Problem of Induction and whether inductive logics are even possible? How realistic is it that we will chance upon really good accounts of the causal fallacies without a good account of causality, including perhaps a resolution of Hume's Problem? How likely is it that we will have something strong to say about the ad ignorantiam short of real insight into the structure of autoepistemic and abductive arguments? ${ }^{37}$ 
Of course, one person's pleasure is another's poison. Efficiently minded argumentation theorists will dislike this link with philosophy on economic grounds. It is a connection which makes the theory of argument too sprawling, too disjointed, and simply too vast for any one theorist's canvass, no matter how big. Better, they say, to handle the fallacies in a more unified and streamlined fashion, in a way that makes the fallacies an entirely self-contained affair. A case in point is the pragmadialectical approach, ${ }^{38}$ which offers a treatment of the fallacies in an overall theory of argument which itself admits of an adequate précis in just five pages of printed text. ${ }^{39}$ Midway between the Gang of Eighteen approach and the pragma-dialetical strategy is the work of Douglas Walton, especially in the past dozen years or so, in which one finds a degree of philosophical engagement within a general framework deriving from pragma-dialectics. ${ }^{40}$

This is not the first time that the desiderata of theoretical economy and theoretical richness have fallen into contention. On the present issue the jury may still be out, but I think I see a recent drift in affection toward economy in fallacy theory at the expense of analytical richness. As I see it, it is a drift in the wrong direction.

\section{Prospects}

\subsection{An Explosion}

No one does a better job than Johnson and Blair, and Hitchcock too, in keeping a running inventory of what's on offer in informal logic. Their reckonings are invariably thorough, judicious, and accurate. Their contributions to the present issue of Informal Logic are no exception. Hitchcock's rehearsals are perhaps a shade more judgmental (no bad thing) than those of Johnson and Blair, but nothing that comes close to excessive or tendentious. Records of this sort have been kept since 1980. They chart the well-being or lack of it of a complex intellectual enterprise involving tens of thousands research man-hours. They attest to the remarkable vigour with which the work of informal logic has been transacted in the past quarter century.

I wonder if it is well and widely understood how much of an intellectual explosion there has been in this period. Sometimes in our summary moments we tend to emphasize the negative. Though irked by it, Johnson and Blair agree that "Informal logic has yet to come together as a clearly defined discipline, one organized around some well-defined and agreed upon systematic techniques that have a definite structure and can be decisively applied by users". ${ }^{41}$ But these are not the conditions under which something is a discipline. If they were, we would know disciplinary impoverishment on a grand scale. We would have lost philosophy, for starters, to say nothing of economics and psychology (and, if Hintikka is right, set theory would be a casualty of these conditions as well). ${ }^{42}$ Even so, it might be true 
that informal logic isn't a discipline. If so, I for one wouldn't mind. What cannot be denied is that it is a research programme, or rather a rich and tumbling congeries of them. As 1 said earlier, deep work on the inductive fallacies requires considerable progress in bringing inductive logic itself to a stable maturity. And telling work on ad verecundiam fallacies demands significant developments in social epistemology. (Here I side with Freeman.)

If anything is true, it is that we have seen too much work in informal logic rather than too little. This explains ratios of good work to bad that we shouldn't be entirely happy with. Informal logic suffers the disadvantage of all disciplines and research programmes with low thresholds of entry. All that's needed is what no one lacks, namely, some confident intuitions about argument. But it is one thing to be seized by some primordial beliefs (as Hertzberger calls them) about arguments; it is quite another thing to know what to do with them. We should envy disciplines whose entry thresholds are forbiddingly high, like recursion theory or topology. Of course it is natural that theratio of good work to not so good is less in informal logic than in recursion theory or topology. They are different animals whose difference matters. Nor is it surprising that over the past fifteen years or so editors have been holding informal logicians to rising standards. Perhaps our self-improvement has not been swift enough; perhaps too much is still let in under benign policies of theoretical pluralism. Indeed perhaps this has bearing on Johnson and Blair's regret that a "major challenge" to informal logic has been its failure to "penetrate the philosophical establishment..."(101).

\subsection{The Mainstream}

How true is this? It is true that philosophers such as Quine will not give informal logic the time of day. Like Peirce, he thinks that there can be no logic of natural language argumentation. On the other hand, present company excepted, establishment philosophers such as Lewis, Goldman, Parsons, Boolos, Sorenson, Adler and Hintikka do publish papers on informal logic and argumentation; and they publish these works in established journals. ${ }^{43}$ No one will say that the ad hominem fallacy or the question of premiss-acceptability is as hot an issue these days as, say, the consciousness question in the philosophy of mind. Johnson and Blair are right in observing that little if any of the informal logic research record has become a staple of Ph.D. programmes in philosophy (other disciples are an exception to this; e.g., the Ph.D. programme in Discourse Analysis at the University of Amsterdam), but the same is true of lots of philosophical research programmes. Even mathematical logic typically rates no more than a mandatory one-semester course, which properly prepared undergraduates could challenge with relative impunity, and sometimes do.

It is also true that these works on informal logic and argumentation published by establishment philosophers in establishment journals have not been much de- 
bated in those circles. But neither have they been much debated by us, whether in "our" circles or "theirs". In saying this, two further points become evident. (A) We don't much debate one another's work. We cite each other, but for the most part we do so without engagement. ${ }^{44}$ Are we too nice (are there, as Johnson and Blair jokingly suggest, too many Canadians in this field)? Are we too shy? Is ours a toothless and over-permissive pluralism? My own view is that it is time long since to take the gloves off and punish views we think misconceived or trivial with a tenacity that recalls the assault of, say, naturalized epistemology on foundationalism and foundationalism's own returning fire. (B) We don't send our work to the establishment journals. Even so, if I may be forgiven a personal aside, $\mathrm{I}^{45}$ have never had a paper on fallacies or related things turned down by an establishment editor. These include, over the years the editors of Nouss, Journal of Philosophical Logic, Notre Dame Journal of Formal Logic, Synthese, Journal of Philosophy, Logique et Analyse, Review of Metaphysics and The Canadian Journal of Philosophy. I infer from this that our overall absence from the establishment record is more our doing than the establishment's .

We should do something about it.

\subsection{The Place of Senior Service Research}

The failure of informal logicians to engage one another is a kind of professional solipsism and, I believe, a wasting problem for informal logic. A further difficulty concerns the relationship between primary research by the senior service, so to speak, and introductory textbooks. In healthy disciplines, textbooks are thoroughly informed by established and up-to-date senior service research. Since primacy attaches to senior service research it can be seen providing the information that trickles down to textbooks. Let us say, then, that in such disciplines textbooks bear a trickle down relationship to primary research. In this informal logic stands truly apart. Its introductory textbooks bear no trickle down relationship to primary research. ${ }^{46}$ In most cases, there is no acknowledgment of such research, never mind an appropriation of it. It is true that the textbook published by Douglas Walton and me in $1982^{47}$ did to some extent draw upon primary research; but it was our own primary research, only a small proper subset of a larger total.

It may bear on the point at hand that in the twenty-seven years since the publication of Kahane's Logic and Contemporary Rhetoric: The Use of Reasoning in Everyday Life one sees a dearth of research monographs on informal logic. Govier's Problems in Argument Analysis and Evaluation, Freeman's Dialectics and the Macrostructure of Arguments and Walton's Argument Structure are exceptions. (So too are Johnson's Manifest Rationality and Christopher Tindale's Acts of Arguing, published since the Boston meetings of 1998.) If we count fallacy theory as part of informal logic, Douglas Walton's numerous monographs are another large exception. But Woods and Walton's 1989 book, Fallacies: Selected 
Papers 1972-1982 is a selection of previously published articles, Blair and Johnson's Informal Logic (1980) is the proceedings of a conference, as is Johnson and Blair's, New Essays in Informal Logic (1994). And Johnson's The Rise of Informal Logic (1996) is a selection of previously published articles, as is Woods' The Death of Argument (2000). Certainly there is nothing in the contemporary research record of the scale or reach (or ambition or clarity of vision) of $A$ System of Logic, written by the greatest informal logician to date, unless the nod goes to Aristotle himself.

It is necessary to ask why there is no trickle down from primary research in informal logic to its textbooks. Three possibilities suggest themselves, all bad. One is that authors of textbooks are too lazy to take command of the primary research record. Another is pedagogical: First year students aren't up to even an introduction to senior service research. The third is that senior service research doesn't warrant consideration by textbook authors. I shall leave these options without further comment, and shall suggest instead that any field that doesn't in a timely way solve its problems of solipsism and the absence of trickle down is not likely to persist as a viable research programme. Johnson and Blair express their concern that our graduate schools are failing to train the next generation of informal logicians. It may turn out not to matter. ${ }^{48}$

\section{Notes}

${ }^{1}$ And-a different thing - a wholly general theory of what we would call "deductive inference". In the interests of space, I shall confine my remarks to the theory of argument.

${ }^{2}$ Parenthesized numerals give page references of the present issue of this journal. Other references are given in endnotes.

${ }^{3}$ Some further insight is offered by the comparatively little that Aristotle has to say about valid immediate inferences, which, of course, are not syllogisms.

4 Cf. Hitchcock (130): "Traditionally an argument is defined as a system composed of premisses and conclusion-a definition which goes back to the early Stoics of the third century BCE." Actually it goes back to Aristotle, but applies only to arguments in this latter abstract sense.

'The point is developed in greater detail in Woods (2000b), Chapter 6.

"In this spirit, Freeman writes (118), "The claim that informal logic is focused on the arguments of the polis seems uncontroversial. Analyzing and evaluating arguments about what we should believe concerning how we may best order our lives together and what we should do as a consequence is central to the informal logic enterprise as standardly interpreted." But this is too narrow; it fits with neither Aristotle's conception of a theory of arguments on the hoof nor with that of present-day theorists, including Freeman himself. Aristotle's theory encompassed arguments about any matter concerning which there was received opinion, as well as arguments from premisses that are in the demonstrative closure of the first principles of the sciences. And concerning how things proceed today, I challenge anyone to show that Freeman's own substan- 
tial contribution to informal logic, Dialectics and the Macrostructure of Arguments, is in any sense an analysis and evaluation of arguments about "what we should believe concerning how we may best order our lives together [etc.] ...", and to show that in its preoccupation with theoretical matters, Freeman's book deviates from the norm. It is true, of course, that Johnson and Blair, in Chapter 11 of the second edition of Logical Self-Defence, give some handy rules of thumb for evaluation advertising messages, these aren't for the most part arguments, and they don't for the most part concern themselves with "how to order our lives together,"

7 Boole's contribution to the mathematical turn in logic resembles Descartes' discovery of analytic geometry. Descartes' showed how to algebraicize plane geometry. Boole showed how to algebraicize the logic of propositions.

${ }^{8}$ Gödel (1986), 369-370: "In consequence of later advances, in particular of . . A.M. Turing's work, a precise and unquestionably adequate definition of the general concept of formal system can now be given. ... Turing's work gives an analysis of the concept of 'mechanical procedure" (alias 'algorithm' or 'computation procedure' or 'finite combinatorial procedure'). This concept is shown to be equivalent with that of a 'Turing machine'. A formal system can simply be defined to be any mechanical procedure for producing formulas".

"Literally "decision problem", but the term is standardly used to denote the problem of finding a mechanical test for validity in first-order logic.

${ }^{10}$ For example: ". . there is a group that advocates a total rejection of formal methods in the study and analysis of argument. An appalling example is the informal logic movement [Johnson and Blair, 1980]. Their attacks, however, are not totally free of the 'strawman fallacy' ..." (Starmans, 1996, 5). This calls to mind a complaint made by Hobbes against a particularly technical manuscript submitted for his opinion: "All scabbed over with algebra!" he thundered. For a more sympathetic rejection, see the passage from Hintikka quoted under the title of this paper.

"This paragraph and the next have benefited from fruitful pressing by John Hoaglund.

${ }^{12}$ Interested readers may wish to consult Woods (200lb).

13 Dewey (1981).

14 See Johnson, (1987), 47-56. See also Fisher (113-114). The fuller story of Quine's naturalization of formal logic is told in Quine (1986).

is Quine (1982), passim.

${ }^{16}$ Quine's collective name for them is "regimentation".

${ }^{17}$ So we may see Peirce as anticipating in a certain way the Quinean notion of canonical notation.

18 I emphasize that this is Quine's view. Shalom Lappin tells me that recent work in linguistics discourages the idea that the distinction between untampered with and canonical languages concurs with the distinction between a weak and strong semantics,

${ }^{19}$ For Freeman on relevance, for example, see Freeman (1992), 219-235. See also Hitchcock (1992), 251-270, and Gabbay and Woods (2001).

${ }^{20}$ On an unsympathetic reading of Freeman (119), the concepts of relevance and ground adequacy haven't fared well in epistemology, so we shouldn't be over-hopeful about their doing any better in informal logic. My own view is that, if epistemology can't deliver the analytical goods, we should drop epistemology and forge more promising alliances with, e.g., computer science, linguistics and psychology.

${ }^{21}$ See, e.g., Quine (1982), 254. Cf. Hansen (1994), 329-337.

${ }^{22}$ But see Woods, Johnson, Gabbay, and Ohlbach (2001).

${ }^{23}$ For a fuller discussion, see Woods (2001a), Chapter 8; and Gabbay and Woods (2002), Chapters 3 and 5 .

${ }^{24}$ Would Freeman disagree that the best account of relevance yet produced has been developed by a pair of linguists? (See Sperber and Wilson, 1995.)

${ }^{25}$ It is true that some reliabilists, e.g., Plantinga, try to get a concept of warrant out of reliabilism. Plantinga's critics think that he fails in this, and so do I. 
${ }^{26}$ I mention in passing the infinite regress to which this pair of statements gives rise.

${ }^{27}$ However, I part company with Fisher on the issue of reflective equilibrium as a justification of principles of inference: Fisher pro and Woods contra. See Woods (2001a), Chapter 8.

${ }^{28}$ Weinstein (1999), 868-871.

${ }^{29}$ See also Finocchairo (1984), 3-8, and (1989), 313-335.

${ }^{30}$ Copi (1995), 84-94.

${ }^{31} \mathrm{See}, \mathrm{e.g}$., van Eemeren and Grootendorst (1992). Their theory means to range "from the formal context of law in an address to the court to the informal context of an ordinary conversation at home" (8).

${ }^{32}$ Honesty compels me to say that when the present writer put this suggestion to Lotfi Zadeh at the first Bonn Conference on Formal and Applied Practical Reasoning in 1996, the father of fuzzy logic was noticeably underwhelmed. For a more detailed discussion of the connection with informal logic, see Woods $(2000 \mathrm{c})$.

${ }^{33}$ For a good sampler of fuzzy logics, Kosko (1991). A more rigorous treatment is Hajek (1998).

For a more detailed discussion of the connection with informal logic, see again Woods (2000c).

${ }^{34}$ A resistance that doesn't prevent him from characterizing fallacy theory - in comparison with analyses of the concept of argument - as an "equally substantial and equally important subject of investigation within informal logic" (130).

${ }^{35}$ Finocchiaro (1981), 13-22.

${ }^{36}$ For further discussion, see Woods (1992), 23-48; reprinted in Woods (2000d).

${ }^{37}$ A fuller discussion can be found in Woods (2000a), 107-134.

${ }^{38}$ Van Eemeren Grootendorst (1987), 283-301. For reservations, see Woods (1992), 42-44, and Woods (1988), reprinted in Woods (2000d). See also Wreen (1994).

34 Starmans (1996), 77-83. Of course, a compact précis implies not that the theory is simple but rather that it is clear, that, in particular, it has a clear structure.

40 Walton is best known for where most of his work actually lies, namely, in fallacy theory. But it is well to note his more broadly oriented contributions, such Walton (1996).

${ }^{41}$ Johnson and Blair (94), quoting Walton and Brinton (1997), 9.

${ }^{42}$ For technical reasons, set theory lacks the resources to determine whether a model of the theory is an intended model. See Hintikka (1996), 176.

${ }^{43}$ Lewis (1982), Boolos (1991), Goldman (1994), Sorensen (1989), Parsons (1996), Adler (1994), Hintikka (1997).

${ }^{44}$ Of course there are exceptions: see, for example Wreen (1994) and Finocchiaro (I995 and 1999).

${ }^{45}$ In many of these cases co-authors are Douglas Walton, Brent Hudak and Hans V. Hansen.

${ }^{16}$ In other fields, or subfields, the trickle down relation is empty, for want of one of the relata. Primary research there is, but textbooks are nowhere in sight. The pragma-dialectical approach to the theory of argument is a case in point. Van Eemeren and Grootendorst have written accessible monographs, relatively free of technical arcana. These works not only showcase the primary research in pragma-dialectics, but they also serve as textbooks. See, e.g., van Eemeren and Grootendorst (1992).

${ }^{47}$ Woods and Walton (1982). A much revised new edition is Woods, Irvine and Walton (2000).

48 I thank my fellow symposiasts in Boston for their stimulating papers and for helpful comments on my oral response. The same gratitude goes to Frans van Eemeren and the late Rob Grootendorst for penetrating criticisms while I was in their midst in 1998, and to Hans Hansen, Harvey Siegel, Jonathan Adler, Robert Pinto, John Hougland and Mark Weinstein. Research was supported by the Social Science and Humanities Research Council of Canada, Professor Bhagwan Dua, Dean of Arts and Science, University of Lethbridge, and Vakgroep Taalbeheersing, Argumentatietheorie en Rhetorica, University of Amsterdam. 


\section{Bibliography}

Adler, Jonathan E, 1994. "Fallacies and Alternative Interpretations", Australasian Journal of Philosophy, 72, 271-282.

Boolos, George. 1991. "Zooming Down the Slippery Slope", Noûs, 25, 395-706.

Copi, Irving M. 1995. "Reconciliation of Formal and Informal Logic", in Frans H. van Eemeren et al. (eds.), Perspectives and Approaches, 84-94. Amsterdam: Sic Sat.

Dewey, John. 1981. Logic: The Theory of Enquiry, 1938, Vol 12 of JoAnn Boydston (ed.), John Dewey: The Later Works, 1925-1953, Carbondale, IL: Southern Illinois University Press.

Eemeren, Frans H. van and Grootendorst, Rob. 1987. "Fallacies in Pragma-Dialectical Perspective", Argumentation 1, 283-301.

Eemeren, Frans H. van and Grootendorst, Rob. 1992. Argumentation Communication and Fallacies, Hillsdale, NJ: Erlbaum.

Finocchiaro, Maurice. 1980. Galileo and the Art of Reasoning, Dordrecht: Reidel.

Finocchiaro, Maurice. 1981. "Fallacies and the Evaluation of Reasoning", American Philosophical Quarterly, 18, 13-22.

Finocchiaro, Maurice. 1984. "Informal Logic and the Theory of Reasoning", Informal Logic, VI, 3-8.

Finocchiaro, Maurice. 1989. "Methodological Problems in Empirical Logic", Communication and Cognition, 22, 313-335.

Finocchiaro, Maurice. 1995. "The Dialectical Approach to Interpretation and Evaluation" in Frans H. van Eemeren et al. (eds.), Perspective and Approaches, 183-195. Amsterdam: Sic Sat,

Finocchiaro, Maurice. 1999. "A Critique of the Dialectical Approach: Part II", in Frans H van Eemeren et al. (eds.), Proceedings of the Fourth International Conference, of The International Society for the Study of Argument, 195-199. Amsterdam: Sic Sat.

Fisher, Alec. 1980. The Logic of Real Arguments, Cambridge: Cambridge University Press.

Freeman, James B. 1991. Dialectics and the Macrostructure of Arguments, Berlin/New York: Foris Publications, PDA 10.

Freeman, James B. 1992. "Relevance, Warrants, Backing, Inductive Support", Argumentation, 6, 219-235.

Gabbay, Dov M.; Johnson, Ralph H.; Ohlbach, Hans Jürgen; and Woods, John (eds.). 2001. Handbook of the Logic of Argument and Inference: The Turn Toward the Practical, Amsterdam: North-Holland, to appear.

Gabbay, Dov M. and Woods, John. 2001. Agenda Relevance: An Essay in Formal Pragmatics, to be published.

Gabbay, Dov M. and Woods, John. 2002. The Reach of Abduction: The Logic of Regressive Inference, to appear.

Gödel, Kurt. 1986. "On Formally Undecidable Propositions of Principia Mathematicia and Related Systems" in Solomon Feferman et al,, (eds.), Kurt Gödel: Collected Works, Vol 1, Oxford: Oxford University Press. 
Goldman, Aalvin I. 1994. "Argumentation and Social Epistemology", Journal of Philosophy, 91, 27-49.

Govier, Trudy.1987. Problems of Argument Analysis and Evaluation, Dordrecht: Foris. Hajek, Petr. 1998. Metamathematics of Fuzzy Logic, Dordrecht and Boston: Kluwer.

Hansen, Hans V. 1994. “Reductio Without Assumptions?" Logique et Analyse, 147-148, 329-337.

Hintikka, Jaakko. 1985. "True and False Logics of Scientific Discovery", Communication and Cognition, 18, 3-14; reprinted in Hintikka (1999), 115-126.

Hintikka, Jaakko. 1996. The Principles of Mathematics Revisited, Cambridge: Cambridge University Press.

Hintikka, Jaakko. 1997. "What Was Aristotle Doing in His Early Logic Anyway?", Synthese, 113, 241-249.

Hintikka, Jaakko. 1999. Selected Papers, vol. 5, Dordrecht and Boston, Kluwer.

Hitchcock, David. 1992. "Relevance", Argumentation, 6, 251-270.

Johnson, Ralph H. 1987. "Logic Naturalized: Recovering a Tradition", in Frans H. van Eemeren et al. (eds.), Argumentation: Across the Lines of Disciplines, Dordrecht: Foris, 47-56.

Johnson, Ralph H. 1996. The Rise of Informal Logic, Newport News, VA: Vale Press.

Johnson, Ralph H. 2000. Manifest Rationality, Mahwah, NJ: Erlbaum 2000.

Johnson, Ralph H. and Blair, J. Anthony (eds.), 1980. Informal Logic, Inverness, CA: Edgepress.

Johnson, Ralph H. and Blair, J. Anthony. 1983. Logical Self-Defence, 2nd edition. Toronto: McGraw-Hill Ryerson. (3rd edition, 1993.)

Johnson, Ralph H. and Blair, J. Anthony (eds.). 1994. New Essays in Informal Logic. Windsor, ON: Informal Logic.

Kahane, Howard. 1971. Logic and Contemporary Rhetoric: The Use of Reasoning in Everyday Life, 1st edition. Belmont, CA: Wadsworth.

Kosko, Bart. 1991. Neural Networks and Fuzzy Systems, Englewood Cliffs, NJ: PrenticeHall.

Lewis, David. 1982. "Logic for Equivocaters", Noins, 16, 431-441.

Parsons, Terence. 1996. "What is an Argument", Journal of Philosophy. 93, 164-185.

Quine, W.V. 1982. Methods of Logic, fourth edition, Cambridge, MA: Harvard University Press.

Quine, W.V. 1986. Philosophy of Logic, second edition, Cambridge, MA: Harvard University Press.

Sorensen, Roy A. 1989. "P, therefore P, Without Circularity", Journal of Philosophy, 88, 245-266.

Sperber, Dan and Wilson, Dierdre. 1995. Relevance, $2^{\text {nd }}$ ed., Oxford: Blackwell.

Starmans, Richard. 1996. Logic, Argument and Commonsense, Tilburg: Tilburg University Print.

Tindale, Christopher W. 1999. Acts of Arguing: A Rhetorical Model of Argument, Albany, NY: SUNY Press.

Walton, Douglas. 1996. Argument Structure: A Pragmatic Theory, Toronto: University of Toronto Press. 
Walton, Douglas and Brinton, Alan (eds.). 1997. Historical Foundations of Informal Logic, Aldershot: Ashgate.

Weinstein, Mark. 1999, "Truth and Argument", in Frans H. van Eemeren, Rob Grootendorst, Anthony Blair and Charles A. Willard (eds.), Proceedings of the Fourth ISSAConference on Argumentation, Amsterdam: SicSat.

Woods, John. 1988. "Pragma-Dialetics: A Radical Departure in Fallacy Theory", ISSA Newsletter, December, 5-15.

Woods, John. 1992. "Who Cares About the Fallacies?", in Frans H. van Eemeren et al. (eds.), Argumentation llluminated, Amsterdam: Sic Sat 1992, 23-48; reprinted in Woods (2000d).

Woods, John. 1994. "Pragma-Dialetics: A Radical Departure in Fallacy Theory", ISSA Newsletter, December 1988, 5-15; reprinted in Woods (2000d).

Woods, John. 2000a. "Slippery Slopes and Collapsing Taboos", Argumentation, 14, 107-134.

Woods, John. 2000b. Aristotle's Earlier Logic, Oxford: Hermes Science, to appear.

Woods, John 2000c. "Has Informal Logic Anything to Learn From Fuzzy Logic", in C.W. Tindale \& H.V. Hansen (eds.), Argumentation at the Century's Turn, St. Catharines, ON: OSSA, to appear.

Woods, John. 2000d. The Death of Argument: Fallacies and Other Seductions, Newport News, VA: Vale Press, to appear.

Woods, John. 2001a. Paradox and Paraconsistency: Conflict Resolution in the Abstract Sciences, Dordrecht and Boston: Kluwer, to appear.

Woods, John. 2001b. "Standard Logics as Theories of Argument and Inference: Deduction", in Dov M. Gabbay, R.H. Johnson, Hans Jürgen Ohlbach and John Woods (eds.), Handbook of the Logic of Argument and Inference: The Turn Toward the Practical, London: King's College and Cambridge: MIT Press, to appear.

Woods, John; Irvine, Andrew; and Walton, Douglas. 2000. Critical Thinking, Logic and The Fallacies, Toronto: Prentice Hall.

Woods, John; Johnson, Ralph H.; Gabbay, Dov M.; and Ohlbach, Hans Jürgen. 2001. "Logic and the Practical Turn", in Gabbay, Johnson, Ohlbach and Woods (2001).

Woods, John and Walton, Douglas. 1982. Argument: The Logic of the Fallacies, Toronto: McGraw-Hill Ryerson.

Woods, John and Walton, Douglas. 1989. Fallacies: Selected Papers 1972-1982, Dordrecht and Providence: Foris.

Wreen, Michael. 1994. "Look, Ma, No Frans", Pragmatics and Cognition, 2, 285-306. Zadeh, Lofti, 1975. "Fuzzy Logic and Approximate Reasoning", Synthese, 30, 407-428.

John Woods

The Abductive Systems Group

University of Lethbridge Lethbridge, Alberta

Canala TIK 3 M4 woods@uleth.ca 